\title{
In Vitro Bioaccessibility of Citrus Pomace Compounds Possessing Health Promoting Properties with Potential to Reduce the Risk of Diabetes ${ }^{\dagger}$
}

\author{
Adriana Maite Fernández-Fernández ${ }^{1,2,3}$, Eduardo Dellacassa ${ }^{4}$, Tiziana Nardin ${ }^{5}$, Roberto Larcher 5 \\ Adriana Gámbaro ${ }^{1}$, Alejandra Medrano-Fernandez ${ }^{1}$ and María Dolores del Castillo ${ }^{2, *}$ \\ 1 Departamento de Ciencia y Tecnología de Alimentos, Facultad de Química, Universidad de la República, \\ General Flores 2124, Montevideo 11800, Uruguay; afernandez@fq.edu.uy (A.M.F.-F.); \\ agambaro@fq.edu.uy (A.G.); amedrano@fq.edu.uy (A.M.-F.) \\ 2 Instituto de Investigación en Ciencias de la Alimentación (CIAL) (CSIC-UAM), C/Nicolás Cabrera, 9 , \\ Campus de la Universidad Autónoma de Madrid, 28049 Madrid, Spain \\ 3 Graduate Program in Chemistry, Facultad de Química, Universidad de la República, General Flores 2124, \\ 11800 Montevideo, Uruguay \\ 4 Departamento de Química Orgánica, Facultad de Química, Universidad de la República, General Flores \\ 2124, 11800 Montevideo, Uruguay; edellac@fq.edu.uy \\ 5 Dipartimento Alimenti e Trasformazione, Centro Trasferimento Tecnologico, Fondazione Edmund Mach \\ di San Michele all'Adige, Via E. Mach, 138010 S. Michele all'Adige (TN), Italy; \\ tiziana.nardin@fmach.it (T.N.); roberto.larcher@fmach.it (R.L.) \\ * Correspondence: mdolores.delcastillo@csic.es; Tel.: +34-910017900 (ext. 953) \\ + Presented at the The 1st International Electronic Conference on Nutrients - Nutritional and Microbiota \\ Effects on Chronic Disease, 02-15 November 2020; Available online: https://iecn2020.sciforum.net/.
}

Published: 30 October 2020

\begin{abstract}
Citrus (mandarin and orange) pomace is an agro-food industrial waste rich in polyphenols and dietary fiber with great potential as functional ingredient. In this work, the chemical composition and in vitro bioaccessibility of health promoting compounds present in raw citrus pomaces (Clemenule and Ortanique mandarins and Navel and Valencia oranges) were studied. In addition, the by-products were employed as food ingredients in cookies and the effect of the food matrix on the bioaccessibility of their bioactive compounds was evaluated. Nobiletin, hesperidin/neohesperidin, tangeretin, heptamethoxyflavone, tetramethylscutellarein, and naringin/narirutin were detected in the citrus samples by UHPLC-MS. Citrus pomaces were in vitro digested mimicking the human oral gastrointestinal conditions and the bioactivity of the digests (antioxidant, carbohydrases modulation and anti-inflammatory effects) was assessed. The bioaccessibility of the antioxidants in the by-products was confirmed by TPC (6.6-11.0 mg GAE/g digest), ABTS (65.5-97.1 $\mu \mathrm{mol} \mathrm{TE} / \mathrm{g}$ digest), ORAC-FL assays (135.5-214.8 $\mu \mathrm{mol} \mathrm{TE} / \mathrm{g}$ digest), and inhibition of ROS formation induced by treatment with tert-butylhydroperoxide $1 \mathrm{mM}$ in intestinal IEC-6 (19-45\%) and CCD-18Co (28-45\%) cells pretreated with the digests at concentrations ranging between 5 and $25 \mu \mathrm{g} / \mathrm{mL}$. Inhibitors of the enzymatic activity of $\alpha$-glucosidase (IC50 3.97-11.42 $\mathrm{mg} / \mathrm{mL}$ ) and $\alpha$-amylase (IC50 58.04-105.68 $\mathrm{mg} / \mathrm{mL}$ ) also remained bioaccessible after in vitro digestion of citrus pomaces. In addition, the bioaccessible compounds in orange pomace samples significantly reduced $(p<0.05)$ the LPS-induced NO production in RAW264.7 macrophages. The digests of orange pomace cookies with the nutrition claims "no-added sugars" and "source of fiber" presented antioxidant and antidiabetic properties, and good sensory quality (6.9-6.7 in a scale of 1 to 9). The results obtained support the feasibility of unfractionated orange pomace as functional ingredient for reducing the risk of diabetes. The health promoting benefits observed in the present research might be, at least partially, associated to flavonoids.
\end{abstract}


Keywords: anti-inflammatory; antioxidant; $\alpha$-amylase; bioaccessibility; citrus pomaces; diabetes; functional cookies; $\alpha$-glucosidase; sensory analysis

\section{Introduction}

Diabetes is considered a XXI century pandemic [1]. Mandarin and orange possess many bioactive compounds such as polyphenols, including flavonoids hesperidin, hesperetin, narirutin, nobiletin, naringin and naringenin, and dietary fiber with potential to reduce the risk or alleviate symptoms of diabetes, such as hyperglycemia [2].

Polyphenols in citrus juice have been proposed to have an important role in glucose-insulin regulation by inhibiting glucose uptake, stimulating insulin secretion and uptake of glucose through the cells, and by modulating the cell signaling, as well as gene expression [3]. New information has recently been published on the possible mechanisms of action by which hesperidin exerts a control of glucose homeostasis [4]. For bioactive compounds exert their positive effect on health, first they have to withstand the processing conditions of the food, be released from the food matrix, be bioaccessible in the gastrointestinal tract, suffer a metabolism and reach the target tissue of interest.

Intestinal absorption and metabolism of glucoside forms of dietary flavanones are complicated and have recently received a lot of attention. Recent studies indicate that a maximum of $30 \%$ hesperidin is absorbed into the small intestine via glucose-linked transporters such as SGLT1 $[5,6]$. However, the exact mechanisms of absorption and metabolism in the enterocyte are not yet clear. It is believed that most of the ingested hesperidin reaches colon, where the colonic microbiota deglycosylates hesperidin producing its corresponding aglycone, hesperetin, which is absorbed by colonocytes [5].

Polyphenols with antidiabetic properties may remain in the citrus pomaces making them valuable by-products of the food industry [2]. The dietary fiber composing the by-product may protect them from degradation during the digestion and food processing. The objective of this research was to gain insight on the chemical composition and in vitro bioaccessibility of health promoting compounds present in raw citrus pomaces with potential to reduce the risk of diabetes or treat the disease. Moreover, the by-products were employed as food ingredients in cookies and the effect of the food matrix on their bioaccessibility was evaluated. The impact of the addition of the byproduct as ingredient in the food sensory quality was studied.

\section{Materials and Methods}

\subsection{Sample Preparation}

Citrus by-products to be used as food ingredients: Pomaces from two mandarin varieties (Clemenule and Ortanique) and two orange ones (Navel and Valencia) were provided by Azucitrus (Paysandú, Uruguay). Mandarin and orange pomaces (wet mixture of pulp, peels, and seeds) were freeze-dried for 4 days to constant weight, milled and stored at $-20{ }^{\circ} \mathrm{C}$ for further analysis.

Food: With the final end to gain insight on the effect of the food processing in the bioaccessibility of polyphenols from citrus pomaces they were used as food ingredients $(10 \% w / w)$. Cookie formulations were prepared with wheat flour, sucralose as sweetener, inulin for obtaining a food with the nutrition claim "source of dietary fiber", butter, sunflower oil, egg, and baking powder.

Fractions containing bioaccessible compounds also called digests: Citrus pomaces and cookies were in vitro digested mimicking the human oral gastrointestinal conditions as described by Hollebeeck et al. [7]. Bile salts were removed by using cholestyramine resin [8]. The desalted samples were frozen and stored for further analysis. 


\subsection{Methodology}

\subsubsection{Analysis of Individual Phenolic Compounds Composing Citrus Pomaces}

Mass spectrometry analysis was employed for the analysis of the polyphenolic profile of the samples. The experiments were performed by UHPLC-MS using a Thermo Ultimate R3000 UHPLC (Thermo Scientific, Sunnyvale, CA, USA), equipped with a Rheodyne 6-port automated switching valve used for on-line clean-up, as described by Barnaba et al. [9].

\subsubsection{Analysis of Bioaccessibility of Bioactive Compounds in Citrus Pomaces and Cookies}

The effect of the digestion process on the bioaccessibility of antioxidants was determined by analysis of the total polyphenol content by Folin reaction, overall antioxidant capacity of the samples employing ABTS and ORAC-FL assays [10], and intracellular ROS formation induced by treating intestinal cells (normal rat small intestine IEC-6 and normal human colon CCD-18Co cells) with tertbutyl hydroperoxide $1 \mathrm{mM}$ using DCFH-DA probe [11]. The anti-inflammatory potential of the bioaccessible compounds was determined by measuring nitric oxide (NO) production induced by lipopolysaccharide (LPS) in RAW264.7 mouse macrophages [10]. Finally, the bioaccessibility of compounds able to modulate the metabolism of carbohydrates was estimated by measuring the enzymatic activity of $\alpha$-glucosidase [10] and $\alpha$-amylase [12].

\subsubsection{Assessment of Food Sensory Quality}

Food quality of the novel cookies was evaluated by sensory analyzes employing 75 consumers ( $40 \%$ male and $60 \%$ female, aged between 18 and 87 years old) recruited at Departamento de Ciencia y Tecnología de Alimentos (Facultad de Química, UdelaR, Uruguay). Overall acceptance was evaluated on a scale of 1 to 9 . Consumers were informed about the composition of the cookie with the novel ingredient (citrus pomace) by the following phrase: "free of sugar cookies containing antioxidants and dietary fiber from orange".

\subsubsection{Statistical Analysis}

Results were expressed as means \pm standard deviation (SD) $(n=3)$. The degree of significance of the statistical differences between the mean values of the studied parameters were determined by Tukey test $(p<0.05)$ using Infostat v. 2015 program. In cell studies, the statistical differences between mean values with $p<0.05$ are indicated with asterisk.

\section{Results and Discussion}

\subsection{Polyhenol Profile of Citrus Pomaces}

Mandarin pomaces showed nobiletin as the main flavonoid in all the samples, followed by hesperidin/neohesperidin, tangeretin, heptamethoxyflavone, tetramethylscutellarein, and naringin/narirutin. Orange pomaces showed nobiletin as the main flavonoid followed by hesperidin/neohesperidin, tangeretin, tetramethylscutellarein, naringin/narirutin, and heptamethoxyflavone. The results are in agreement with previous reports [13,14], being those flavonoids known for their bioactive properties [2].

\subsection{Bioaccessibility of Bioactive Compounds Composing Citrus Pomaces}

Results shown in Table 1 and Figure 1 support the bioaccessibility of antioxidants including polyphenolic compounds. The results are in agreement with previous polyphenols bioaccessibility studies on citrus [15]. The intracellular ROS formation in the normal small intestinal cells of rats (IEC6) was significantly reduced $(p<0.05)$ by the samples under study (data not shown). However, only the orange samples were able to cause a significant prevention $(p<0.05)$ of the formation of radicals in normal human colon cells (CCD-18Co). Similar results were found by others employing citrus 
samples in HepG2 cells [16]. To the best of our knowledge, this is the first time the antioxidant effect of citrus bioaccessible fractions in normal human intestinal cells is shown.

Table 1. Bioaccessibility of antioxidants from mandarin and orange pomaces.

\begin{tabular}{ccccc}
\hline Analysis & $\begin{array}{c}\text { Clemenule } \\
\text { Mandarin }\end{array}$ & $\begin{array}{c}\text { Ortanique } \\
\text { Mandarin }\end{array}$ & $\begin{array}{c}\text { Navel } \\
\text { Orange }\end{array}$ & $\begin{array}{c}\text { Valencia } \\
\text { Orange }\end{array}$ \\
\hline $\begin{array}{c}\text { Total phenolic } \\
\text { compounds } \\
(\text { mg GAE/g sample })\end{array}$ & $9.98 \pm 0.51^{\mathrm{b}}$ & $11.00 \pm 0.65^{\mathrm{b}}$ & $10.80 \pm 1.67^{\mathrm{b}}$ & $6.62 \pm 0.38^{\mathrm{a}}$ \\
$\begin{array}{c}\text { ABTS } \\
(\mu \mathrm{mol} \mathrm{TE} / \mathrm{g} \text { sample }) \\
\text { ORAC-FL }\end{array}$ & $90.1 \pm 1.5^{\mathrm{b}}$ & $92.0 \pm 2.0^{\mathrm{bc}}$ & $65.5 \pm 4.4^{\mathrm{a}}$ & $97.1 \pm 10.4^{\mathrm{c}}$ \\
$(\mu \mathrm{mol}$ TE/g sample $)$ & $135.5 \pm 22.2^{\mathrm{a}}$ & $232.5 \pm 26.7^{\mathrm{b}}$ & $214.8 \pm 20.0^{\mathrm{b}}$ & $207.8 \pm 29.0^{\mathrm{b}}$ \\
\hline
\end{tabular}

Results are mean values \pm SD $(n=3)$. Different letters indicate significant differences (Tukey, $p<0.05$ ) between values in the same row.

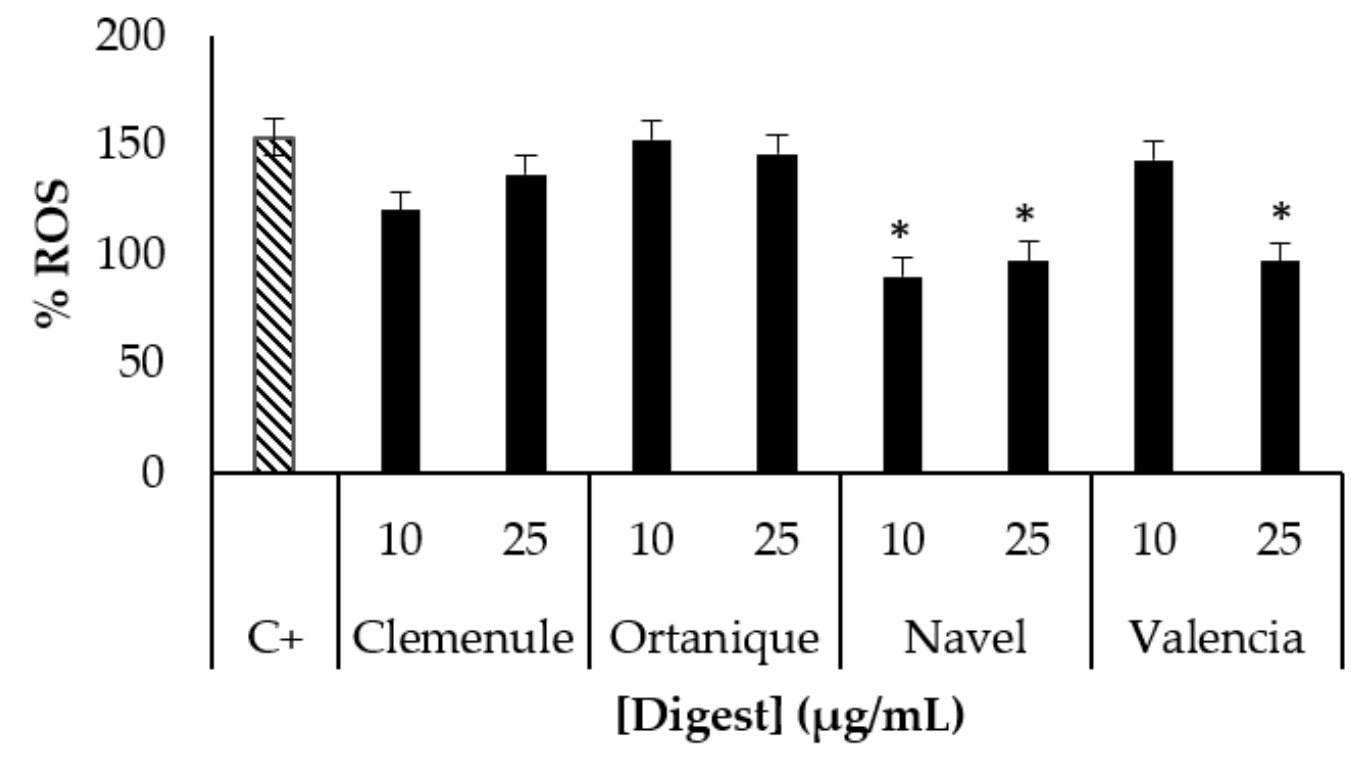

Figure 1. Induced ROS formation in human intestinal cells (CCD-18Co) treated with digests of Clemenule and Ortanique mandarin and Navel and Valencia orange pomaces prior to the oxidative damage. Normal human colon cells were treated with samples during $24 \mathrm{~h}$ followed by coadministration of oxidative agent (tert-butyl hydroperoxide) and sample for $30 \mathrm{~min}$. Bars represent mean values while error bars denote standard error of the mean (SEM).

Data on NO formation in RAW264.7 can be observed in Figure 2. Citrus flavonoids have been reported for their anti-inflammatory effects [17-19] being in accordance with the current results. 


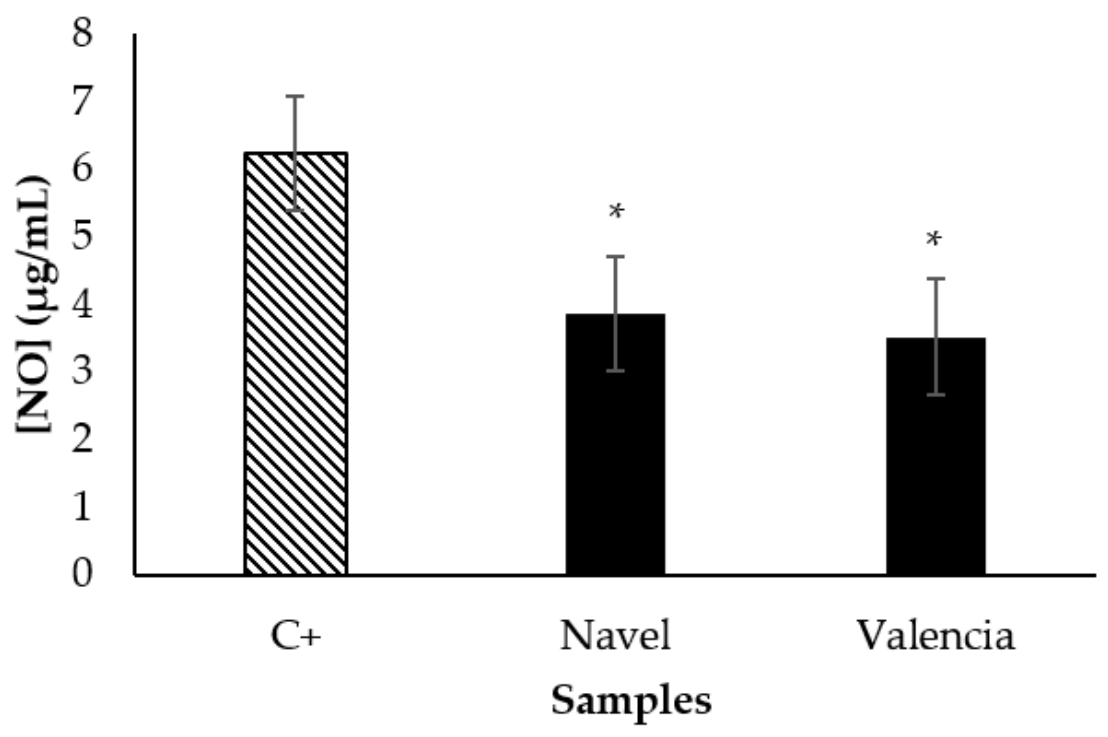

Figure 2. Effect of the orange pomace bioaccessible compounds $(250 \mu \mathrm{g} / \mathrm{mL})$ in the formation of NO in RAW216.7 macrophages. Cells were treated with samples during $24 \mathrm{~h}$ followed by coadministration of LPS and sample during $24 \mathrm{~h}$. Bars represents mean values while error bars denote standard error of the mean (SEM).

Results shown in Table 2 support the bioaccessibility of inhibitors of carbohydrases highlighting the effect on $\alpha$-glucosidase enzyme. Citrus flavonoids have been reported for inhibiting these carbohydrases [20].

Table 2. Bioaccessibility of inhibitors of the enzymes $\alpha$-glucosidase and $\alpha$-amylase from mandarin and orange pomaces.

\begin{tabular}{ccccc}
\hline Analysis & $\begin{array}{c}\text { Clemenule } \\
\text { Mandarin }\end{array}$ & $\begin{array}{c}\text { Ortanique } \\
\text { Mandarin }\end{array}$ & Navel Orange & $\begin{array}{c}\text { Valencia } \\
\text { Orange }\end{array}$ \\
\hline $\begin{array}{c}\alpha \text {-glucosidase } \\
(\mathrm{IC} 50, \mathrm{mg} / \mathrm{mL}) \\
\begin{array}{c}\alpha \text {-amylase } \\
(\mathrm{IC} 50, \mathrm{mg} / \mathrm{mL})\end{array}\end{array}$ & $3.97 \pm 0.97 \mathrm{a}$ & $4.93 \pm 0.41^{\mathrm{a}}$ & $11.42 \pm 0.89 \mathrm{~b}$ & $5.09 \pm 0.39 \mathrm{a}$ \\
\hline
\end{tabular}

Results are mean values \pm SD $(n=3)$. Different letters indicate significant differences (Tukey, $p<0.05)$ between values in the same row.

\subsection{Food Matrix Effect on the Bioaccessibility of Bioactive Compounds and Food Sensory Quality}

As can be observed in Table 3, antioxidants and inhibitors of glucosidase remained bioaccessible after the digestion of the food containing orange pomaces as ingredient, being in accordance with other authors reports of cookies with other by-products [8]. Data on antioxidant capacity and $\alpha$ glucosidase activity seem to indicate a protective effect of the cookies food matrix against the degradation of the bioactive compounds during the digestive process. According with the data shown in Table 3, Navel orange pomace may be the best candidate among the studied samples to be employed as ingredient in the formulation of cookies for reducing the risk of diabetes. On the other hand, the overall consumers' acceptance of the orange pomace cookies was of 6.86 and 6.68 for Navel and Valencia varieties, respectively (scale 1-9), with no significant differences $(p>0.05)$. All together the results support the food quality of the cookies formulated with orange by-products and their potential for reducing the risk of diabetes. The new formulation of cookies is sugar free and contains dietary fiber and bioactive compounds able to reduce the risk of diabetes that may remain bioaccessible after food digestion. 
Table 3. Bioaccessibility of antioxidants and inhibitors of $\alpha$-glucosidase in cookies based on orange pomaces.

\begin{tabular}{cccc}
\hline Analysis & Control Cookie & Navel Cookie & Valencia Cookie \\
\hline Overall antioxidant capacity & & & \\
ABTS $(\mu$ mol TE/g sample) & $82.36 \pm 3.73^{\mathrm{a}}$ & $99.30 \pm 3.68^{\mathrm{b}}$ & $100.81 \pm 12.98^{\mathrm{b}}$ \\
ORAC-FL ( $\mu$ mol TE/g sample) & $74.66 \pm 9.09^{\mathrm{a}}$ & $115.95 \pm 21.73^{\mathrm{b}}$ & $118.02 \pm 6.41^{\mathrm{b}}$ \\
Inhibition of carbohydrase activity & & & \\
$\alpha$-glucosidase $(\mathrm{IC} 50, \mathrm{mg} / \mathrm{mL})$ & $5.66 \pm 0.61^{\mathrm{b}}$ & $3.90 \pm 0.20^{\mathrm{a}}$ & $4.62 \pm 0.43^{\mathrm{b}}$ \\
\hline
\end{tabular}

Results are expressed as mean values \pm SD $(n=6)$. ANOVA analysis was performed by row using Tukey test. Different letters indicate significant differences $(p<0.05)$ tested by row.

\section{Conclusions}

UHPLC-MS analysis of mandarin and orange pomaces showed nobiletin as the main flavonoid. The presence of flavonoids with antidiabetic properties such as hesperidin and its aglycone in the samples was also confirmed by employing this advanced analytical tool. Data on total phenol content, ABTS and ORAC-FL support the bioaccessibility of antioxidants composing citrus pomaces. The orange pomace bioaccessible compounds significantly inhibited $(p<0.05)$ the induced intracellular ROS formation in normal human intestinal cells (CCD-18 cells). In addition, these samples produced significant reduction $(p<0.05)$ of nitric oxide production on LPS-induced RAW264.7 macrophages after in vitro simulation of digestion, indicating anti-inflammatory properties. Moreover, orange pomaces resulted to be suitable ingredients for cookies since they were accepted by the consumers. A new formulation of sugar free cookies containing dietary fiber and bioactive compounds (antioxidant and inhibitors of glucosidase) able to reduce the risk of diabetes was obtained. In conclusion, our results support the feasibility of unfractionated orange pomace as functional ingredients for reducing the risk of diabetes. The bioactive properties found in the current study may be at least partially associated to the flavonoids composing citrus pomaces.

Author Contributions: A.M.F.-F. performed chemical and biological assays, data curation, interpretation and global integration of the results, and writing the original draft of the manuscript as well as review and editing; E.D. contributed to writing the original draft of the manuscript and the critical manuscript revision; T.N. and R.L. contributed on mass spectrometry analyses; A.G. contributed on sensory study design; A.M.-F. contributed on the interpretation of the global results and founding acquisition; M.D.d.C. contributed on study design, the interpretation of global results, manuscript revision, and founding acquisition. All authors have read and agreed to the published version of the manuscript.

Funding: This research was funded by ANII (grant POS_NAC_2016_1_130292), program EMHE-CSIC (grant MHE-200003) and PEDECIBA-UdelaR.

Acknowledgments: The authors would like to thank Azucitrus S.A. (Paysandú, Uruguay) for providing citrus pomaces.

Conflicts of Interest: The authors declare no conflict of interest.

\section{References}

1. WHO. Noncommunicable Diseases. Available online: https://www.who.int/news-room/factsheets/detail/noncommunicable-diseases (accessed on 25 November 2019).

2. Fernández-Fernández: A.M.; Dellacassa, E.; Medrano-Fernandez, A.; Del Castillo, M.D. Citrus Waste Recovery for Sustainable Nutrition and Health. In Food Wastes and By-Products: Nutraceutical and Health Potential; Campos-Vega, R., Oomah, B.D., Vergara-Castañeda, H.A., Eds.; John Wiley \& Sons Ltd.: Hoboken, NJ, USA, 2020; pp. 193-211. ISBN 9781119534105.

3. Kerimi, A.; Gauer, J.S.; Crabbe, S.; Cheah, J.W.; Lau, J.; Walsh, R.; Cancalon, P.F.; Williamson, G. Effect of the flavonoid hesperidin on glucose and fructose transport, sucrase activity and glycaemic response to orange juice in a crossover trial on healthy volunteers. Br. J. Nutr. 2019, 121, 782-792, doi:10.1017/S0007114519000084.

4. Xi, B.; Li, S.; Liu, Z.; Tian, H.; Yin, X.; Huai, P.; Tang, W.; Zhou, D.; Steffen, L.M. Intake of fruit juice and incidence of type 2 diabetes: A systematic review and meta-analysis. PLoS ONE 2014, 9, e93471. 
5. Aschoff, J.K.; Riedl, K.M.; Cooperstone, J.L.; Högel, J.; Bosy-Westphal, A.; Schwartz, S.J.; Carle, R.; Schweiggert, R.M. Urinary excretion of Citrus flavanones and their major catabolites after consumption of fresh oranges and pasteurized orange juice: A randomized cross-over study. Mol. Nutr. Food Res. 2016, 60, 2602-2610, doi:10.1002/mnfr.201600315.

6. Actis-Goretta, L.; Dew, T.P.; Lévèques, A.; Pereira-Caro, G.; Rein, M.; Teml, A.; Schäfer, C.; Hofmann, U.; Schwab, M.; Eichelbaum, M.; et al. Gastrointestinal absorption and metabolism of hesperetin-7-Orutinoside and hesperetin-7-O-glucoside in healthy humans. Mol. Nutr. Food Res. 2015, 59, 1651-1662, doi:10.1002/mnfr.201500202.

7. Hollebeeck, S.; Borlon, F.; Schneider, Y.-J.; Larondelle, Y.; Rogez, H. Development of a standardised human in vitro digestion protocol based on macronutrient digestion using response surface methodology. Food Chem. 2013, 138, 1936-1944, doi:10.1016/j.foodchem.2012.11.041.

8. Martinez-Saez, N.; Hochkogler, C.M.; Somoza, V.; del Castillo, M.D. Biscuits with no added sugar containing stevia, coffee fibre and fructooligosaccharides modifies $\alpha$-glucosidase activity and the release of GLP-1 from HuTu-80 cells and serotonin from Caco-2 cells after in vitro digestion. Nutrients 2017, 9, 694, doi:10.3390/nu9070694.

9. Barnaba, C.; Dellacassa, E.; Nicolini, G.; Nardin, T.; Serra, M.; Larcher, R. Non-targeted glycosidic profiling of international wines using neutral loss-high resolution mass spectrometry. J. Chromatogr. A 2018, 1557, 75-89, doi:10.1016/j.chroma.2018.05.008.

10. Fernández-Fernández, A.M.; Iriondo-DeHond, A.; Dellacassa, E.; Medrano-Fernandez, A.; del Castillo, M.D. Assessment of antioxidant, antidiabetic, antiobesity, and anti-inflammatory properties of a Tannat winemaking by-product. Eur. Food Res. Technol. 2019, 245, 1539-1551, doi:10.1007/s00217-019-03252-w.

11. Iriondo-DeHond, A.; Ramírez, B.; Escobar, F.V.; del Dolores Castillo, M. Antioxidant properties of high molecular weight compounds from coffee roasting and brewing byproducts. Bioact. Compd. Health Dis. 2019, 2, 48-63, doi:10.31989/bchd.v2i3.588.

12. Li, K.; Yao, F.; Du, J.; Deng, X.; Li, C. Persimmon Tannin Decreased the Glycemic Response through Decreasing the Digestibility of Starch and Inhibiting $\alpha$-Amylase, $\alpha$-Glucosidase, and Intestinal Glucose Uptake. J. Agric. Food Chem. 2018, 66, 1629-1637, doi:10.1021/acs.jafc.7b05833.

13. Gattuso, G.; Barreca, D.; Gargiulli, C.; Leuzzi, U.; Caristi, C. Flavonoid Composition of Citrus Juices. Molecules 2007, 12, 1641-1673, doi:10.3390/12081641.

14. Zou, Z.; Xi, W.; Hu, Y.; Nie, C.; Zhou, Z. Antioxidant activity of Citrus fruits. Food Chem. 2016, 196, 885-896, doi:10.1016/j.foodchem.2015.09.072.

15. Cilla, A.; Rodrigo, M.J.; Zacarías, L.; De Ancos, B.; Sánchez-Moreno, C.; Barberá, R.; Alegría, A. Protective effect of bioaccessible fractions of citrus fruit pulps against $\mathrm{H} 2 \mathrm{O} 2$-induced oxidative stress in Caco-2 cells. Food Res. Int. 2018, 103, 335-344, doi:10.1016/j.foodres.2017.10.066.

16. Chen, Z.-T.; Chu, H.-L.; Chyau, C.-C.; Chu, C.-C.; Duh, P.-D. Protective effects of sweet orange (Citrus sinensis) peel and their bioactive compounds on oxidative stress. Food Chem. 2012, 135, 2119-2127, doi:10.1016/j.foodchem.2012.07.041.

17. Wang, J.; Qi, Y.; Niu, X.; Tang, H.; Meydani, S.N.; Wu, D. Dietary naringenin supplementation attenuates experimental autoimmune encephalomyelitis by modulating autoimmune inflammatory responses in mice. J. Nutr. Biochem. 2018, 54, 130-139, doi:10.1016/j.jnutbio.2017.12.004.

18. Gosslau, A.; Chen, K.Y.; Ho, C.-T.; Li, S. Anti-inflammatory effects of characterized orange peel extracts enriched with bioactive polymethoxyflavones. Food Sci. Hum. Wellness 2014, 3, 26-35, doi:10.1016/j.fshw.2014.02.002.

19. Nakajima, V.M.; Moala, T.; Caria, C.R.P.; Moura, C.S.; Amaya-Farfan, J.; Gambero, A.; Macedo, G.A.; Macedo, J.A. Biotransformed citrus extract as a source of anti-inflammatory polyphenols: Effects in macrophages and adipocytes. Food Res. Int. 2017, 97, 37-44, doi:10.1016/j.foodres.2017.03.034.

20. Sahnoun, M.; Trabelsi, S.; Bejar, S. Citrus flavonoids collectively dominate the $\alpha$-amylase and $\alpha$-glucosidase inhibitions. Biologia 2017, 72, 764-773, doi:10.1515/biolog-2017-0091.

Publisher's Note: MDPI stays neutral with regard to jurisdictional claims in published maps and institutional affiliations.

(C) 2020 by the authors. Submitted for possible open access publication under the terms and conditions of the Creative Commons Attribution (CC BY) license (http://creativecommons.org/licenses/by/4.0/). 